\title{
Gums and resins of Ethiopia
}

\author{
Mulugeta Lemenih and Habtemariam Kassa
}

\section{Key messages}

If executed properly, the production and marketing of gums and gum resins from natural forests need not affect the environmental services that dry forests provide. We recommend eight key points to policymakers and other stakeholders interested in enhancing the role of gums and resins in local livelihoods.

- Enact a Federal Forest Act to facilitate the implementation of the 2007 Forest Proclamation. Based on the Act, regional guidelines that clarify the rights and responsibilities of producers in accessing and managing the dry-forest resource base could be issued.

- Mobilise key actors for collective action to better manage dry forests.

- Facilitate the involvement of local communities in using gums and resins with concomitant responsibility to sustainably manage the resource.

- Build extension and support services to assist local communities and private companies to produce more and better-quality products and to ensure sustainable supply.

- Develop production, storage and marketing guidelines and establish certification and monitoring systems to build buyers' confidence.

- Improve the market information system.

- Upgrade the capacity of the value chain, improving its governance and building capacity for value-adding and processing (e.g. extraction of essential oils from frankincense), to create employment opportunities, reduce marketing and shipment costs and significantly increase the economic gains for producers and traders.

- Organise producers into cooperatives and traders into associations to improve their technical and managerial capacity and to strengthen their bargaining power.
This brief examines the importance of gums and resins to local livelihoods and the national economy in Ethiopia. It looks at the resource base, potential and actual production levels and economic contribution, as well as the constraints of the subsector. The brief concludes by assessing the prospects for gums and resins in the international market, and highlights necessary measures to achieve improvements in forest management and product handling and marketing.

\section{Importance of gums and resins in Ethiopia}

Dry forests comprise the largest forest resources in Ethiopia. Their contribution to rural livelihoods, the national economy and ecosystem stability is significant, although not yet properly accounted for. An important feature of Ethiopia's dry forests is their richness in Acacia, Boswellia and Commiphora species. These trees are the source of gums and gum resins, which are the most important export commodities of the Ethiopian forestry sector. During the past decade, the total export volume and foreign currency earnings from gums and gum resins have increased. However, it is important that this increase in the volume of products is accompanied by responsible forest management.

\section{Resource base: Coverage, species diversity and current status}

Current estimates of the area of well-stocked dry forest and woodlands for the production of gums and gum resins in Ethiopia vary from $28550 \mathrm{~km}^{2}$ to $43350 \mathrm{~km}^{2}$. Although about 35 species of Acacia, Boswellia and Commiphora have been identified as potential producers of commercial gums and gum resins, currently gums and gum resins are collected from only a few species. Products collected include gum arabic (from Acacia senegal var. senegal, A. senegal var. kerensis, A. seyal var. seyal and $A$. seyal var. fistula); frankincense (from Boswellia papyrifera, B. neglecta, B. rivae, B. microphylla and B. ogadensis); and Commiphora gum resins (opoponax, myrrh and other 


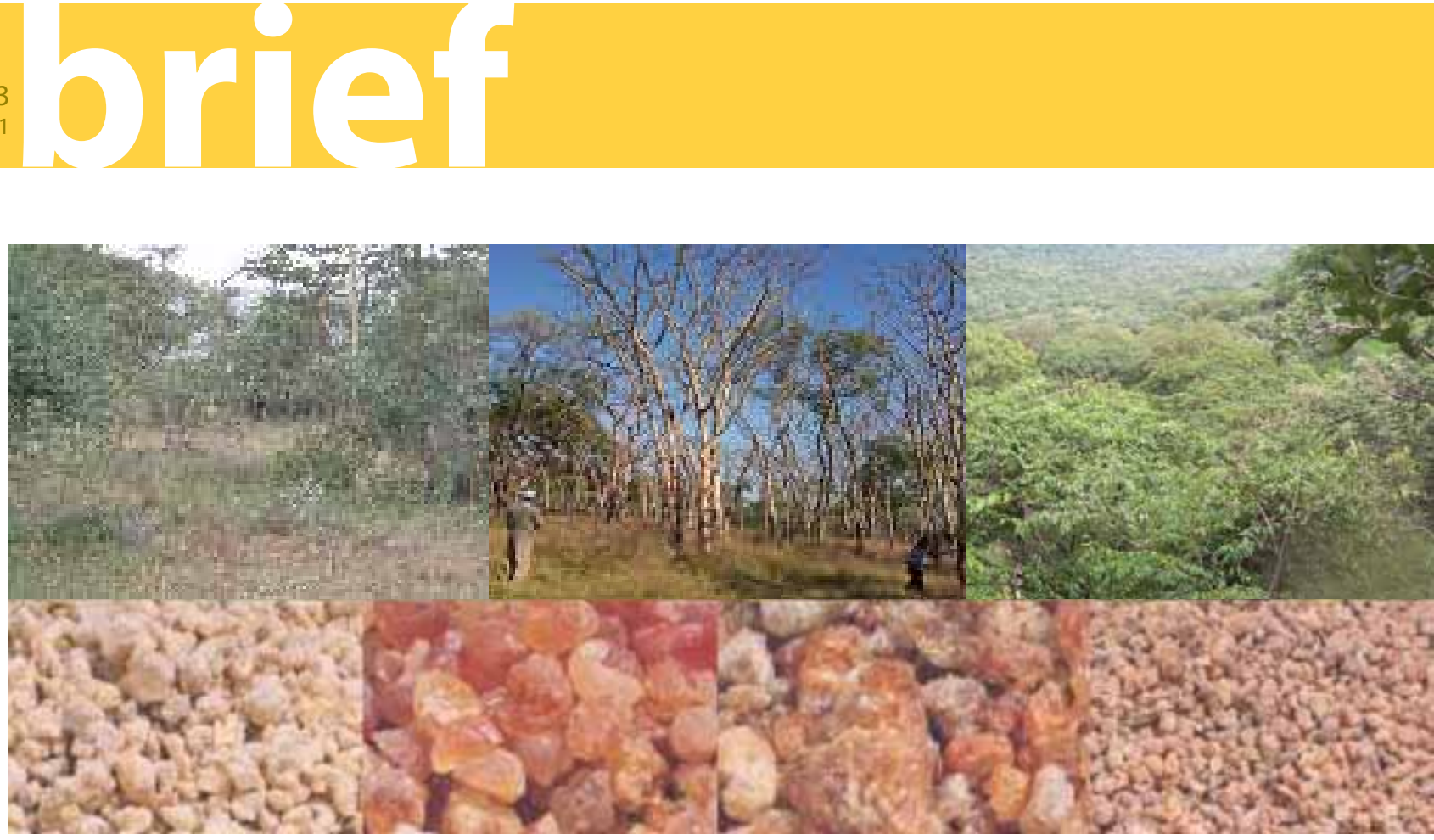

Photo 1. Partial views of dry forests of Ethiopia (upper left: Acacia-Commiphora forest in Borana, southern Ethiopia; upper middle and right: Boswellia forest in Metema, north-western Ethiopia) and their gum resins (bottom row, from left to right: frankincense, gum arabic, gum talha and myrrh).

myrrh-like gums, mainly from Commiphora myrrha, C. guidotti and C. erythraea) (Photo 1).

Assessment of the current status of the resource base shows a worrying trend. Most of the Boswellia stands are characterised by a lack of saplings growing in their natural environment, despite large numbers of seedlings observed immediately following the rainy season.

For example, the population structure of B. papyrifera (Figure 1) indicates weak regeneration and an unstable population. As no forest management plan is in place in major producing areas, tapping is uncontrolled and enrichment planting is uncommon. Furthermore, there are no formal protective or control measures against fire and grazing.

\section{Potential and actual production}

Assuming a population density of 50-80 trees per hectare and a production potential of $0.25-1.0 \mathrm{~kg}$ per tree per year, the estimated potential annual production of gums and gum resins in Ethiopia ranges from 35000 to 114000 metric tonnes. The wide range in the estimate is due to the lack of reliable data on the resource base and productivity levels. Although Ethiopia has been trading in these products for centuries, the production and marketing of gums and resins remain underdeveloped, with the annual export volume at less than 5000 tonnes. This indicates how the export market of gums and gum resins is still underdeveloped. According to exporters, the amounts of gum and gum resin products in the market are insufficient to meet export demands, and products in the local market are of inferior quality. On the other side, producers complain that the low prices they get for

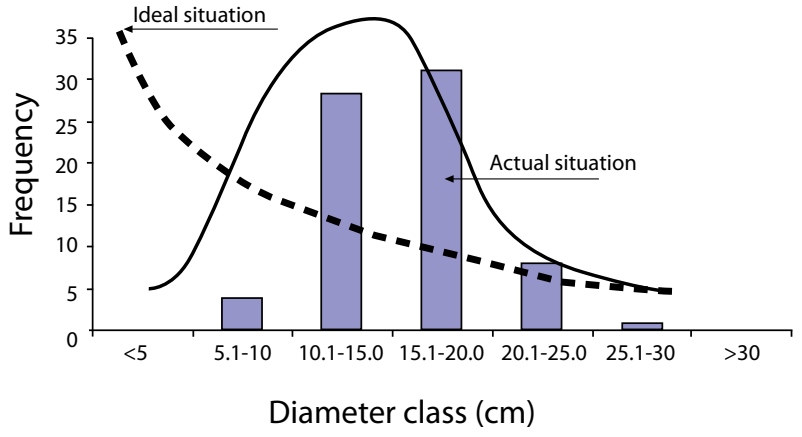

Figure 1. Population structure of B. papyrifera in Metema district, north-western Ethiopia

Source: Lemenih et al. (2007)

products do not give them sufficient incentive to collect and sell greater quantities or to seek to improve quality.

\section{Economic contribution}

Gums and gum resins contribute to local livelihoods, in terms of both cash income, gained by selling products to buyers, and subsistence value. Several gums and gum resins are used as herbal medicines, insecticides and hygienic and sanitation detergents. The annual domestic consumption is expected to grow. Currently, an estimated 10000 metric tonnes per annum (estimated value of US\$12 million) is consumed locally, $60 \%$ of which is used in religious establishments. The exported volume remains much lower than the domestic market, but has been showing an increasing trend since the mid-1990s (Figure 2), due to trade liberalisation and involvement of private companies in the export market. Currently, private companies account for about two-thirds of the export 


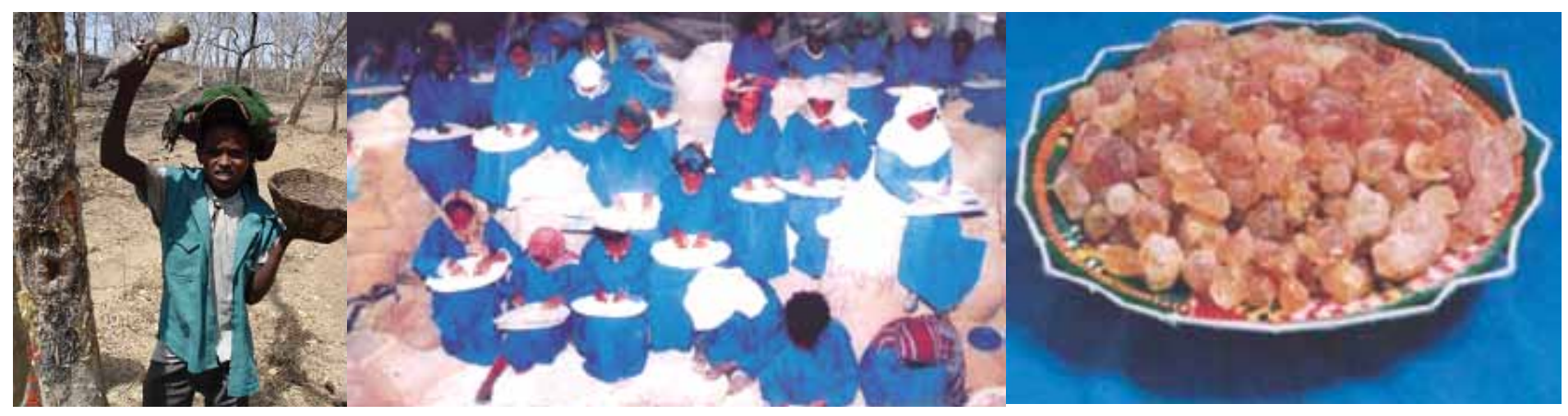

Photo 2. The gums and gum resins industry creates employment opportunities for men, who do the tapping (left), and women, who sort and grade the collected resins (centre) into products such as gum Arabic (right) ready for packing.

Volume exported (tonnes)

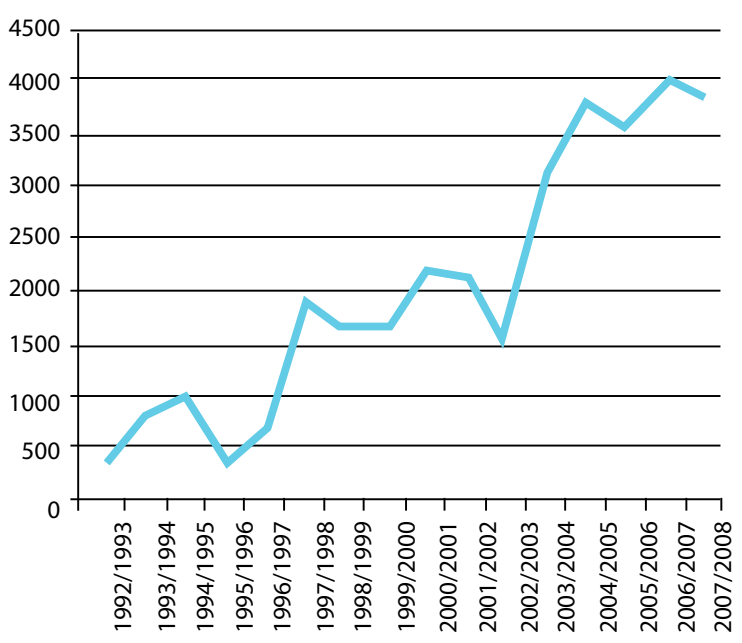

Value ('000 Birr)

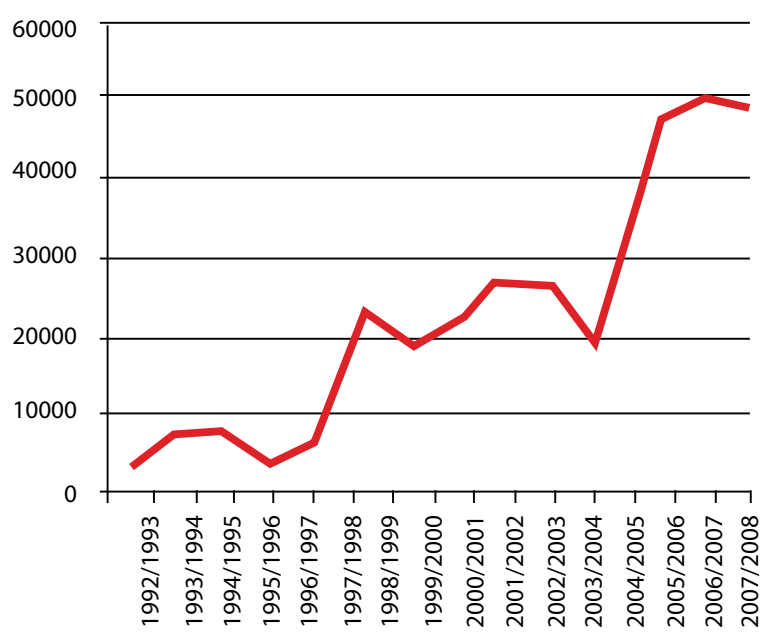

Value ('000 Birr)

Figure 2. Quantity in tonnes (left) and value in Birr (right) of gums and resins exports from Ethiopia, 1992-2008

volume and earnings. During the 2007/08 fiscal year, Ethiopia exported 4612 tonnes of gums and resins, to the value of 74 million Birr (about US\$7.7 million). The major importing countries in that period were China, United Arab Emirates, Germany, Egypt and Guatemala. China has become the largest importer of frankincense.

Companies engaged in gum and gum resin trade create employment opportunities for the rural and urban poor (Photo 2). Along the production and marketing chains, these companies employ close to 35000 people each year. This number far exceeds the employment opportunities created by the country's wood-based industries. Furthermore, individual producers engaged in the production and sale of gums and gum resins earn considerable income. For instance, a survey conducted in the Gode, Moyale, Negale and Bale areas of southern Ethiopia indicated that a collector could earn up to US\$172/year, close to the average per capita income of the nation. The volume of products - and hence income-increases during drought periods, when agropastoralists in the study area collect and sell more gums and gum resins.

\section{Constraints on the gums and gum resins subsector}

The following constraints hinder the development of the gums and gum resins subsector in Ethiopia.

- There is a lack of reliable data on the resource base and its actual production potential.

- Several problems arise in relation to access to and management of the resource base. In some areas, communities own and manage the resource, whereas in others (e.g. Amhara Region) local community access to the resource is severely restricted. Only commercial producers with adequate capital are allowed to collect and sell gums and resins. These companies are given 


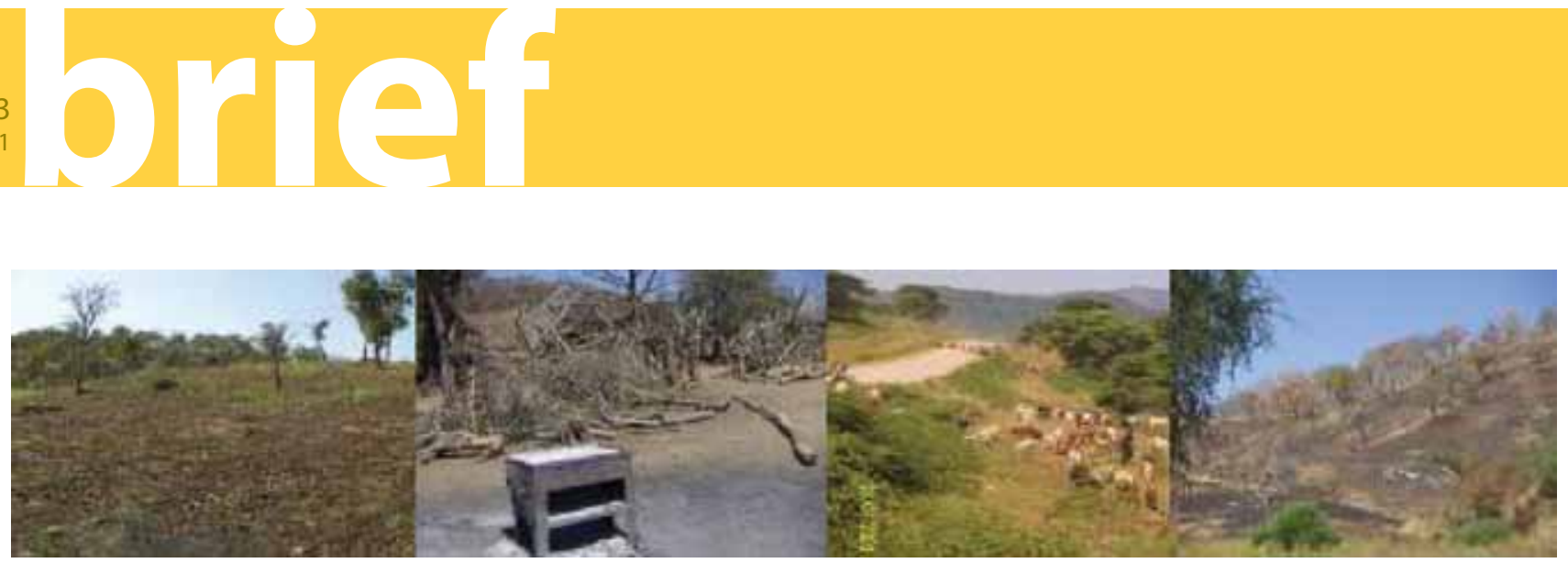

Photo 3. Predominantly Boswellia forest in north-western Ethiopia faces pressure from forest conversion to cropland, excessive harvest for firewood, overgrazing and forest fire.

licences to exploit an area for only 1 year. There are no forest management plans nor is there any monitoring system to ensure that gum collecting and exporting companies are managing the forest responsibly.

- The resource base is affected by overgrazing, forest fire, severe tapping, excessive wood harvest and conversion of forest areas to commercial (by investors) and staple (by settlers) croplands (Photo 3).

- There is a lack of relevant market information on demand for volume and quality of gums and gum resins in the export and domestic markets (e.g. no information is available on the volumes stored annually or sold locally).

- Improper collection (e.g. mixing products of different species and of different qualities) and storage practices reduce product quality. Poor quality control and lack of certification by authorities influences ability to enter certain export markets.

- Underdevelopment of the infrastructure in major producing areas increases production and marketing costs. Inadequate market information and long marketing chains result in low farm gate prices, which in turn cause irregular supply to formal markets and increased crossborder trade.

- Producers'technical capacity and bargaining power remain weak as they have not organised themselves.

- There is no internationally recognised and/or nationally approved grading system for frankincense, and the current grading system bears little relation to product quality in terms of essential oils. There are no production and marketing guidelines for producers and traders to help increase product quantity and quality for the export market. Thus, export of raw products continues because of the limited knowledge and capacity for value-adding and processing.

- The government's emphasis on forestry is inadequate and the institutional capacity of the mandated ministry to support the development of the forestry sector is weak (e.g. extension and support services for gum production and marketing are almost non-existent).

\section{Future prospects}

The number of countries importing gum and gum resin products from Ethiopia has increased, now reaching nearly 60. Given their wide range of applications, and a growing preference among consumers for natural products, the global demand for gums and gum resins is likely to remain high. Imports by European countries are expected to grow significantly if forests and forest products can be certified. Thus, producing diversified and more forest products according to required quality standards while sustainably managing the forest would benefit local communities and the country generally.

\section{Main reference}

Information for this brief was drawn from the forthcoming 'Opportunities and challenge for sustainable production and marketing of gums and resins in Ethiopia' edited by M. Lemenih and H. Kassa, CIFOR, Bogor, Indonesia. policies and practices that affect forests in developing countries. CIFOR is one of 15 centres within the Consultative Group on International Agricultural Research (CGIAR). CIFOR's headquarters are in Bogor, Indonesia. It also has offices in Asia, Africa and South America. 